\title{
Solving Word Problems Involving "Ratio" Concept of the Fifth - Grade Students: A Study in Vietnam
}

\author{
Ngo Truc Phuong', Nguyen Phu Loc ${ }^{2, *}$ \\ ${ }^{1}$ Faculty of Education, Bac Lieu University, Vietnam \\ ${ }^{2}$ School of Education, Can Tho University, Vietnam
}

Received March 21, 2020; Revised May 19, 2020; Accepted June 24, 2020

Copyright $(2020$ by authors, all rights reserved. Authors agree that this article remains permanently open access under the terms of the Creative Commons Attribution License 4.0 International License

\begin{abstract}
The ratio is a mathematical concept that is useful in real life. In Vietnam, at an elementary level, students are acquainted with ratios in grade 4 through word problems and arithmetic operations. In grade 5, students continue to be familiar with proportional quantities and percentages which are related to ratios. In secondary schools, students will continue to study the slope of a straight line and trigonometric concepts which are essential applications of the ratio. Therefore, it is essential to help Vietnamese students understand the concept of a ratio and successfully solve word problems involving ratios. It should be an indispensable objective in teaching mathematics at primary levels in general and in grades 4-5 in particular. The paper presents the results of the analysis of mathematical content related to the ratio in primary mathematics textbooks of Vietnam and an experiment on solving word problems related to ratios of the fifth-grade students. It was found out that the misconceptions of ratio and lack of solving strategies cause primary school students' difficulties in solving word problems involving ratio. From that, the authors propose some solutions to improve students' abilities in solving these problems.
\end{abstract}

Keywords Difficulty in Word Problem Solving, Misconception, Mathematical Solving Strategy, Ratio, Word Problem - Solving, Primary Mathematics Education

\section{Introduction}

It cannot be denied that ratio and proportion are fundamental for students to understand across multiple topics in mathematics and science because of their wide applications. Therefore, ratio and proportion are two important options that must be taught in primary schools [1]. According to Dougherty et al., while teaching the concept of ratio in elementary school, teachers should pay attention to three features as follows [5]:

(1) The relationship between the quantities in a ratio is multiplication in nature, not addition;

(2) A unit rate of quantity is always found although one of the numbers in the ratio is not a factor (or multiple) of the other number;

(3) Equivalent ratios are not necessary integral multiples of another ratio.

It is also essential to connect ratios to fractions. Using a variety of strategies in order to solve ratio problems reflects students' understanding of equivalent fractions and multiplication and division $[12,13,14]$.

In research involving 49 Grade 5 students, Andini \& Jupri found that students were confused in understanding ratio and proportion and faced difficulties in completing word problem with different contexts. One of the causes was that the topic of ratio and proportion in textbooks was presented partially [1].

There is a strong correlation between the contents that are taught and the achievements of the students [9]. The primary students who enable to resolve word problems will virtually depend on what they have learnt to solve these kinds of problems.

\section{* Mathematical Misconception}

According to Allen (2007), mathematical misconceptions are faulty and incorrect ideas resulting from students' misunderstanding about a mathematical idea or concept. Misconceptions are often based on applications of inappropriate rules or generalizations [5]. Misconceptions and errors are related. Errors are symptoms of the underlying conceptual structures that are the cause of errors, while misconceptions are the cause of systematic conceptual errors (Olivier, 1992). An error may result from a misconception or other factors like carelessness. Spooner stated that A misconception is indicator of poor understanding (cited [11]). 
In term of ratio and proportional reasoning, Dougherty et al (2017) mentioned three types of a misconception that lead to students' difficulties in solving problems, including additive versus multiplicative comparisons, the incorrect conceptualization of fractions, and lack of covariational thinking. Misconception about additive and multiplicative comparisons is a popular problem of primary students. Teachers can prevent misconceptions by using multiple representations, making a table in teaching ratio and proportional reasoning, especially equivalent ratio [5].

\section{* Mathematical Problem-solving Strategy}

Main strategies used in solving problems are to make a systematic list, guess and check, make a drawing, look for a pattern, write an equation, solve a similar or simpler problem, work back, construct a table, and reasoning. It can be stated that the level of learning the problem-solving strategies is different between students.

According to Charles et al. (1992), it is necessary to introduce such mathematical problem-solving strategies to primary or middle school students as to guess-check-revise, draw a picture, act out the problem, use objects, choose an operation, solve a simpler problem, make a table, look for a pattern, make an organized list, write an equation, use logical reasoning, and word backward (cited in [17]).

In research into students' difficulties in solving mathematical word problems from their teachers' perspectives, Seifi et al. [17] showed that students in elementary grades had a weak foundation because sometimes their teachers taught them inappropriate strategies, such as the strategy of finding keywords. They indicated that the students' difficulties in solving word problems resulted from text difficulties, unfamiliar contexts in problems and use of inappropriate strategies. They also suggested that teachers teach students to use some strategies like looking for a pattern, drawing a picture, and rewording the problems.

Dougherty et al. proposed that students use "looking for a pattern" or "constructing a table" strategy to show equivalent ratios and solve word problems related to ratios [5]. Besides, using "identifying a pattern" problem is an effective strategy to solve word problems of proportional quantities [10].

\section{The Research Questions}

From the above reviews, it can be seen that primary school students have difficulties in learning ratio, including the understanding of the concept of a ratio and solving problems relating to ratios. This paper will focus on two following research questions:

$R Q 1$. What have Vietnam primary school students learnt about ratio as well as to solve a word problem involving ratio?

$R Q 2$. What difficulties do students encounter in solving word problems involving ratio?

- $\quad R Q 2 a$. What errors do students make in solving word problems with finding a ratio of fractions or decimals?

- $R Q 2 b$. What impacts of the lack of the concept of equivalent ratio to students' difficulties in solving word problems involving percentages are?

- $\quad R Q 2 c$. How do students choose strategies for solving word problems involving ratio?

\section{Methodology}

\subsection{Content Analysis (for Answering the RQ1)}

Currently, in Vietnam, there is only one set of Math textbooks available for all primary schools as Toan 1 (Grade 1), Toan (Grade 2), Toan 3 (Grade 3), Toan 4 (Grade 4) and Toan 5 (Grade 5). The content of the ratio only appears in Toan 4 [6] and Toan 5 [7]. We used content analysis method to clarify the content of ratio and related problems which appeared in the textbooks (Toan 4 \&Toan 5).

\subsection{Investigation (for Answering the RQ2)}

\subsubsection{Participants}

Experimental subjects were 35 fifth grade students in primary schools in Bac Lieu city. These students have learned of ratio, proportion, and percentage according to Vietnam Mathematics curriculum (textbooks: Toan 4, Toan 5). The study was carried out in January 2020.

\subsubsection{Student testing: In order to find the answers to the} $R Q 2$, we asked students to solve six following exercises related to the ratio by writing their answers in the paper test. Through the results of students' work, we discover their errors, difficulties and strategies used to solve word problems related to the ratio.

Exercise 1: $\frac{2}{5}$ of the marks at the end of term are for classwork, $\frac{1}{3}$ for homework and the remainder for the end of term test. What is the ratio of classwork marks to homework marks? What fraction of the total marks is for the test?

Exercise 2: In a baking recipe, every 4.5 gram of sugar is mixed with 22.5gram of flour to make one cake. What is the ratio between the amount of sugar and flour in the recipe?

The pedagogical intent of Exercises 1 and 2 are to test students' understanding of the concept of ratio as a division involving fractions and decimals because Vietnamese textbooks do not present this division. They aim to answer 
the $Q R 2 a$.

Exercise 3: Binh checks the height of two trees after a month of growing. One tree grows from 0.9 meters to 1.0 meter. The other grows from 0.8 meters to 0.9 meters. Binh says that these two trees are not the same in growth. What is your opinion?

The pedagogical intent of Exercise 3: The problem is for testing students' application of ratio in real contexts. This type of problem is absent in Toan 4 and Toan 5. How do students understand ratio in quantitative comparison? Which strategy do they choose to solve an unfamiliar problem? (for answering the $R Q 2 c$ ) We supposed that students are able to be confused to distinguish between division and subtraction.

Exercise 4: A library buys a number of Science textbooks which are four times as many Mathematics textbooks. The cost of a Mathematics textbook is $20,000 \mathrm{VND}$ while a Science cost $15,000 \mathrm{VND}$. The amount of money to buy all these textbooks is $1,520,000 \mathrm{VND}$. How many Mathematics textbooks does the library buy?

The pedagogical intent of Exercise 4: The purpose of Exercise 4 is to determine the impact of lack of concept of equivalent ratios of students in solving multi-step problems (for answering the $R Q 2 b$ ). Although equivalent fractions appear in Toan 4, equivalent ratios are not mentioned. This can cause some errors in solution reasoning of ratio problems. In the problem, it is easy for students to think about linking data with the "sum-ratio" problem, which is very familiar with them. However, their solution can be wrong at the first step if students do not determine correctly main quantities like the number of textbooks and the amount of money for buying textbooks. In the problem, the total purchase amount is given, but there is no ratio between money amounts of two types of textbooks. Similarly, there is a ratio of the number of Math and Science textbooks, but the total of textbooks is not available. In this case, the strategy of using the line diagram may be the first option in students' work.

Exercise 5: There are 40 pupils in Class 5/1. The ratio of boys to girls is $\frac{3}{7}$. What per cent of pupils in the class are girls?

Exercise 6: In an aquarium, $25 \%$ of fishes are goldfishes. If a number of goldfishes that are equal to the available fishes are added into the aquarium, now what per cent of fishes in the aquarium are goldfishes?

The pedagogical intent of Exercises 5 and 6 are to examine whether students realize the relationship between percentage and ratio or not (for answering the $R Q 2 c$ ). When solving familiar problems, students are often instructed by teachers to choose calculations and ignore the representation by diagrams immediately. To solve Exercise 5 , instead of converting ratio to per cent, many students who learnt to formulate of percentage not linking with ratio often find percentage by division $a: b$ to have a decimal and converting decimal into a percent. Exercise 6 is to determine students' understanding of changing of ratio in different contexts as well as their ability in converting per cent to a fraction. In addition, Exercises 5 is to show some cases in which students use the "sum-ratio" problem inappropriately. The "sum-ratio" problem is very familiar with the 4th graders in solving word problems, so in grade 5 they often link this problem with finding solutions for non-routine problems without concerning the relationship of given data. These exercises also aim to determine whether representing per cent by the pictural model is used or not.

\section{Results and Discussions}

\subsection{The ratio in Vietnamese Primary Mathematics Textbooks}

\subsubsection{The Contents of Ratio in Toan 4}

In Vietnamese primary Mathematics curriculum [2], the ratio is introduced at Grade 4 for students to acquaint with its concept and solve "sum-ratio" or "difference-ratio" problems [4]. After learning fractional topics, the fourth graders are taught about the concept of a ratio and some problems related to ratios. They are "sum-ratio" and "difference-ratio" problem, map scale and applications.

- The concept of a ratio is based on the notion of fraction and division. For example, the ratio of $\mathrm{A}$ to $\mathrm{B}$ is $4: 5$ or $\frac{4}{5}$. Ratio is a comparison of part-to-part, part-to-whole, and whole-to-part. The fraction representing a ratio is often in the simplest form.

- The "sum-ratio" (or "difference-ratio") problem refers to finding two numbers if their sum (or difference) and ratio are known. In these problems, the ratio is often given in the form of a fraction and the question is to determine two numbers satisfying the requirement (see Figure 1).

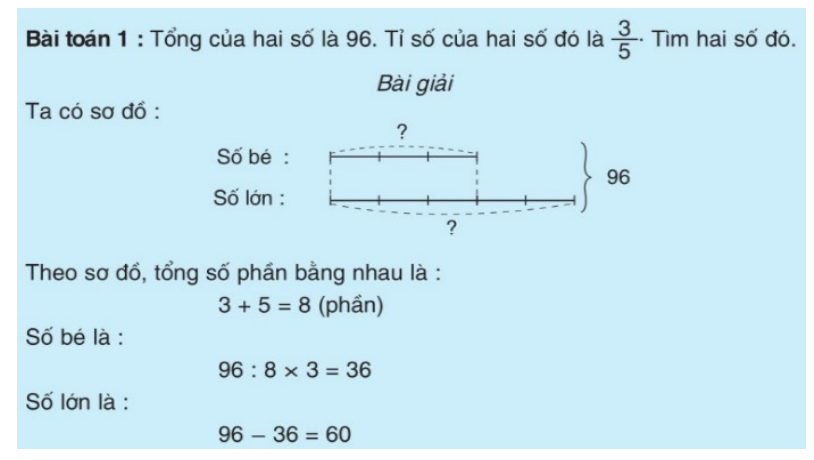

Figure 1. An illustration of "sum-ratio" problem in Toan 4 (Hoan et al, 2014, p.147) [6] 
Their solving process often consists of three following steps:

(1) Representing the ratio of two numbers by two lines divided into equal parts by the value of numerator and denominator (the strategy of using a line diagram).

(2) Finding the sum (or difference) of numbers of equal parts and calculating value of a part;

(3) Multiplying respectively value of a part by numerator and denominator to calculate the given numbers.

- Map scale and applications:

Fractional numerals represent the map scale with a numerator of 1. From the given map scale and minimized length, the requirement of "map scale" problem is finding the real length which is multiplied between the minimized length and the denominator of the fraction representing the given map scale. Sometimes, the requirement of the problem is to convert the measurement unit.

To support for learning ratio, some knowledge of fraction is introduced previously in Toan 4, including equivalent fractions, converting fractions to lowest terms, reducing fractions to the same denominator, four operations of fractions, and finding a fraction of a whole number, etc. Value of the fraction of a whole is the result of multiplication, the fraction and the whole, such as finding $\frac{2}{3}$ of 12 by calculating $\frac{2}{3} \times 12=8$.

\subsubsection{The Contents of Proportional Quantities and} Percentages Related to the Ratio in Toan 5

\section{* Problems of Proportional Quantities}

Toan 5 presents two methods to solve problems of directly proportional quantities as follows:

- The Ratio Method refers to determining a constant factor of two given values of the same quantity. For example, if travelling 4 kilometres is in 1 hour then travelling 12 kilometres is in 3 hours (because 3 hours is three times as much as 1 hour, in this case, the constant factor is 12:4=3).

- The Unitary Method entails finding a value equivalent to one unit of quality and then using that value as a factor to multiply by. For example, if we travel 12 kilometres in 3 hours then in 1 hour (a unit of time) we travel 4 kilometres, so in 5 hours we travel 20 kilometres.

Table 1. The distribution of types of exercise relating to ratio in Vietnam primary textbooks

\begin{tabular}{|c|c|c|c|c|}
\hline Grade-level & Type of tasks & Number of periods & Number of exercises & Frequency \\
\hline \multirow{5}{*}{ Toan 4} & Find ratio of two items & 1 & 4 & $4 / 44$ \\
\hline & Solve "sum-ratio" problem & 4 & 16 & $16 / 44$ \\
\hline & Solve "difference-ratio" problem & 4 & 14 & $14 / 44$ \\
\hline & Find a fraction of a whole number & 1 & 1 & $1 / 44$ \\
\hline & Map scale and applications & 5 & 9 & $9 / 44$ \\
\hline \multirow{5}{*}{ Toan 5} & Solve proportional problem & 3 & 9 & $9 / 31$ \\
\hline & Convert per cent to fraction and vice versa & 1 & 3 & $3 / 31$ \\
\hline & Find the percentage of two quantities & 2 & 5 & $5 / 31$ \\
\hline & Find the value of the percentage of a given quantity & 2 & 8 & $8 / 31$ \\
\hline & $\begin{array}{l}\text { Find the whole number from the given part and } \\
\text { percentage }\end{array}$ & 2 & 6 & $6 / 31$ \\
\hline
\end{tabular}

These methods are also considered essential strategies for solving proportional problems. However, when the value of one unit of the quantity is decimal, the unitary method is not used because the problem of proportional quantities is learned earlier than the concept of decimal numbers. Besides, if the value of the quantity is not multiple of other quantity, students do not solve problems by the ratio method.

\section{* Problems of Percentage}

In Toan 5, percentage plays an important role. The concept of percentage is built from the perspective of ratio. It represents the ratio of two quantities. The relationships among decimal, fraction, and percentage are illustrated by numeral conversions.

There are three types of word problems involving percentage, including: express one quantity as a percentage of another, find the percentage of a given quantity, and find the whole from the given part and percentage. In these problems, all of the operations are carried out with decimal numbers [15].

Some different types of task related to percentage are:

- Recognizing percentage of two quantities.

- Reading and writing percentage. Writing fraction as a percentage and vice versa.

- Writing decimal as a percentage and vice versa.

- Knowing four operations: addition and subtraction of percentages, multiplication of percentage by whole numbers, and division of percentage by non-zero natural numbers.

According to Chung et al. [4], the percentage does not belong to numeral knowledge. Fifth graders learn percent mainly through solving three types of word problems involving percentage. Besides, representing percentage as a fraction is not a major task in problem-solving involving percentage. At the same time, techniques used for natural number and decimal are prioritized in Grade 5 Mathematical syllabus [15].

\subsubsection{The Distribution of Tasks and Learning Time}

The distribution of the number of periods (45 minute/1 period) and types of tasks (exercises) related to ratio, proportional problems, and percentage in textbooks is summarized in Table 1. 
It can be seen that time used to learn the concept of the ratio is limited while the "sum- ratio" and "difference-ratio" problem get priority to practice. In grade 5, finding a ratio of two decimals or fractions is not introduced while students frequently approach sum (difference)-ratio problem with decimal or fractions. Moreover, the relationship of ratio and proportion reasoning as well as a percentage is rarely mentioned in the textbooks. The previously mentioned concepts for Grade 5 students to build up the foundation that they need to understand ratio are only fractions.

\subsubsection{Discussions}

In Toan 4, almost ratios are represented by the notation of the fraction $\frac{a}{b}$, not division $a: b$, except conceptual part. The concept of equivalent ratios is not mentioned. Most of the contents related to the ratio in grade 4 are focused on "sum-ratio" or "difference-ratio" problems. Toan 4 has no tasks which form "a ratio is a multiplicative comparison of two numbers" as well as "ratio as a division" to students. To understand ratios, students use what they know about fractions in which their numerator and denominator are whole numbers.

In relation to ratio, proportional quantities and percentages are introduced in grade 5. However, Toan 5 does not emphasize relationships. In describing the proportional relationship of two quantities, Toan 5 does not emphasize their ratio but introduce two methods of verbal solving mentioned above. In addition, as solving routine word problems related to percentages in grade 5, students sometimes need to use of percentage as a ratio, but they do not know it is necessary to apply such conversion. Toan 5 presents an algebraic solution for each type of problem [8]. Besides, the pictorial illustrations are rare in the textbooks. The concept of percentage is introduced at first by 10-by-10 grid only once. After that, students learn the percentage without both diagram and 10-by-10 grid.

Regarding solving problem strategies, Toan 4 and 5 introduce four main strategies, including using the line diagram, using the unitary method, selecting a calculation, and returning to a familiar problem. The line model method is often used as an effective strategy to solve various types of word problems. Students usually use the line model at first to acquaint with and understand the steps in the solution of a problem. After some of the practising, they perform to solve the problem without the line model.

\subsection{Results of Investigating Students and Discussions}

The results of students' responses are summarized in Table 2 .
Table 2. Students' distribution of responses to the test

\begin{tabular}{|c|c|c|c|c|}
\hline Exercise & Correct & $\begin{array}{c}\text { Correct } \\
\text { partly }\end{array}$ & Wrong & $\begin{array}{c}\text { No } \\
\text { answer }\end{array}$ \\
\hline 1 & 20 & 2 & 0 & 13 \\
\hline 2 & 18 & 0 & 5 & 12 \\
\hline 3 & 5 & 0 & 30 & 0 \\
\hline 4 & 7 & 15 & 8 & 5 \\
\hline 5 & 35 & 0 & 0 & 0 \\
\hline
\end{tabular}

\section{* Exercises 1 and 2}

In Exercise 1, the students' answers included two ways: (1) reducing fractions to the same denominator and (2) dividing $\frac{2}{5}$ by $\frac{1}{3}$. In the first way, 10/35 students carried out reducing fractions to the same denominator as $\frac{2}{5}=\frac{6}{15}, \frac{1}{3}=\frac{5}{15}$. Next, they showed "the ratio of classwork marks to homework marks is $\frac{6}{5} "$ (with $8 / 10$ responses) and "the ratio is $\frac{5}{6}$ " (with $2 / 10$ responses). Two incorrect responses indicated that students had an error in applying for part-to-part order. In the second way, 10/35 students used dividing $\frac{2}{5}$ by $\frac{1}{3}$ and had the correct answer.

In Exercise 2, 18 students solved the problem in the following ways:

" $4.5: 22.5=0.2=\frac{2}{10}=\frac{1}{5}$, the ratio is $\frac{1}{5} "$

or" $22.5: 4.5=5$, the ratio is $\frac{1}{5}$ "

Some students did not understand ratio as a division or perform the division inappropriately (see Figure 2).

In Exercises 1 and 2, there are more than half of the students who can find the correct answer. They can perform fractional operations effectively. However, it has been observed that the $5^{\text {th }}$ - grade students have difficulty in understanding ratio from the perspective of the division and part-to-part formula.

\section{* Exercise 3}

Most students chose subtraction and conclude that the two trees had the same growth (see Figure 3).

The concept of ratio was not exploited in solving the problem. Students did not realize that this is a problem of comparing two ratios $(0.9 /(0.8)$ and $(1.0) /(0.9)$ or comparing two ratios (0.9-0.8) / (0.8) and (1.0-0.9) / (0.9). Another response is that students had not been familiar with the ratio of decimals, so they did not perform to compare $\frac{0.1}{0.9}$ and $\frac{0.1}{0.8}$. Therefore, they stopped doing the problem and submitted the answer. In this case, all students 
gave an incorrect response to Exercise 3 (using subtraction where division is appropriate) showed that students had misconception on growth ration (and growth rate) in applying the concept of ratio as a comparison in context. The strategy of "choosing an operation" used in this exercise is unappropriated.

\section{* Exercise 4}

Like our prediction, in the first solution, many students opted for "the ratio is $\frac{1}{4}$ and the sum is $1,520,000$ " to solve Exercise 4 according to the "sum-ratio" problem. The answer was a decimal number (see Figure 4). The incorrect solution resulted from reasoning "ratio between amount money of buying two types of textbooks equals the ratio of numbers of textbooks".

Another incorrect response was the ratio of the number of textbooks equal ratio $\frac{4}{3}$ (the lowest fraction of $\frac{20000}{15000}$ ) between the amount money of two types of textbooks. The answer was also a decimal number.

The strategy of "using a line diagram" used in this exercise is appropriate, but students determined ratio incorrectly. It proved that a lack of the concept of equivalent ratios caused some reasoning errors.

The students' outcome of problem 4 also revealed that students did not know how to use the strategy of "searching for a pattern" or "constructing a table" to find patterns related to the ratio and proportion of the situation. If students use one of these strategies, it is not difficult to provide the correct solution to this problem. For example, if they group 1 math book and 4 science books into one, the price will be 80,000 , they will easily infer the number of math books and scientific books.

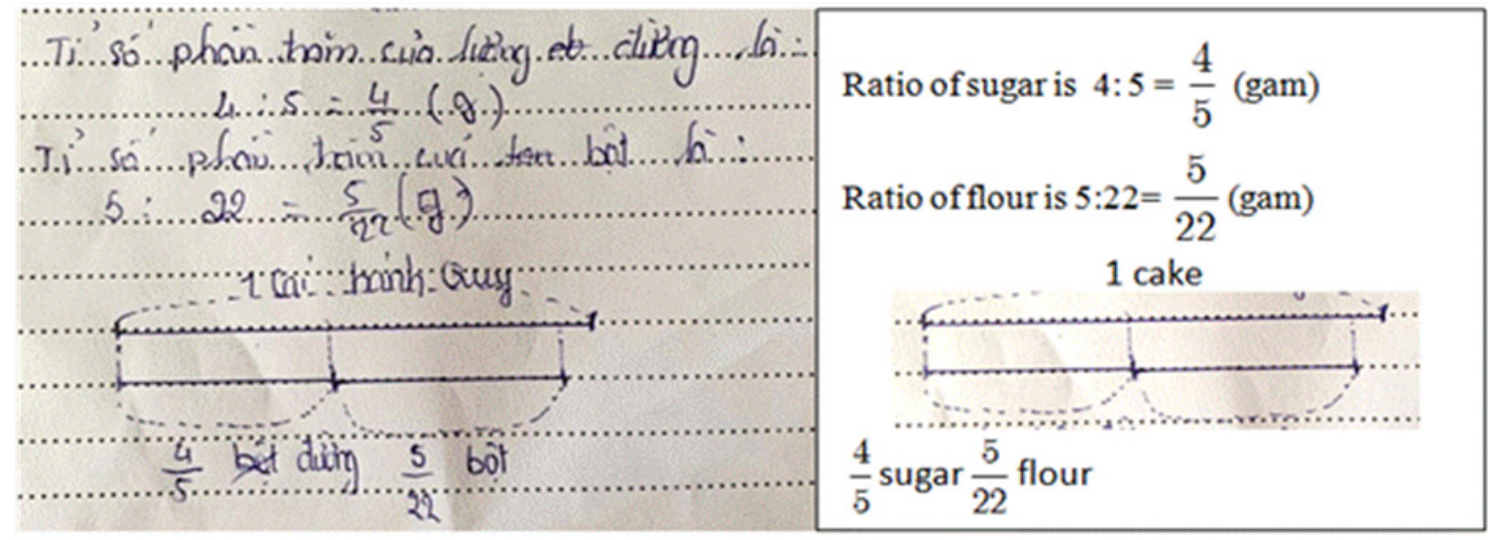

Figure 2. A students' incorrect answer to Exercise2

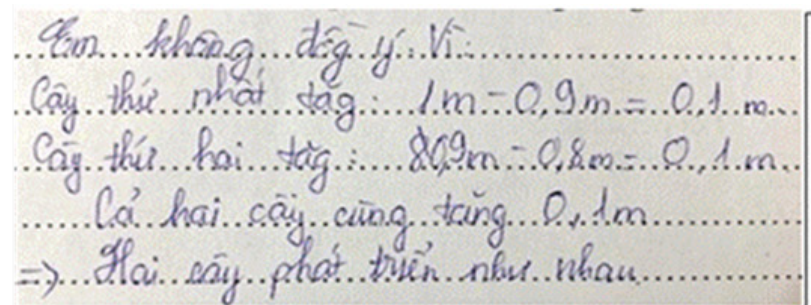

\section{I don't agree because \\ The first tree increase $1 \mathrm{~m}-0.9 \mathrm{~m}=0.1 \mathrm{~m}$ \\ The second tree increase$$
0.9 \mathrm{~m}-0.8 \mathrm{~m}=0.1 \mathrm{~m}
$$ \\ Both trees are increased by $0.1 \mathrm{~m}$ so they have the same development.}

Figure 3. A students' incorrect answer to Exercise3

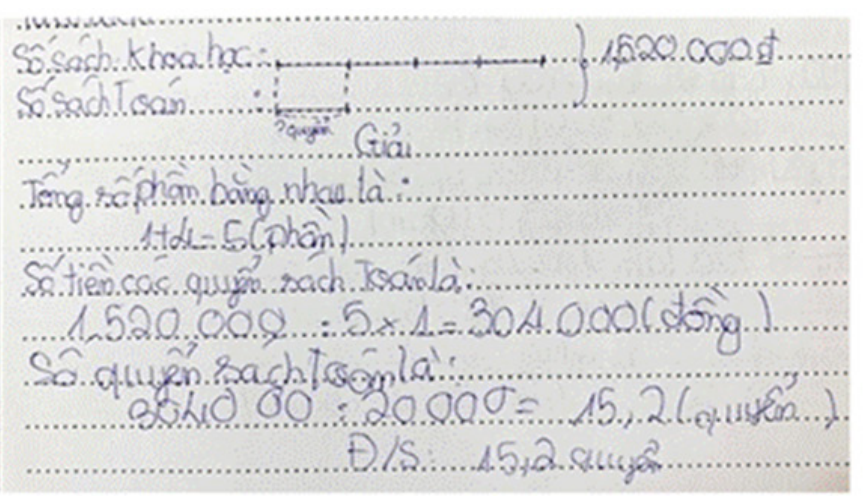

Total of equal parts is

$1+4=5$ (parts)

Amounts of money to buy Math books is 1520000:5x1=304000 (VND)

The number of Math books is

304000:20000 = 15.2 (books)

Answer: 15.2 books

Figure 4. A students' incorrect answer to Exercise 4 


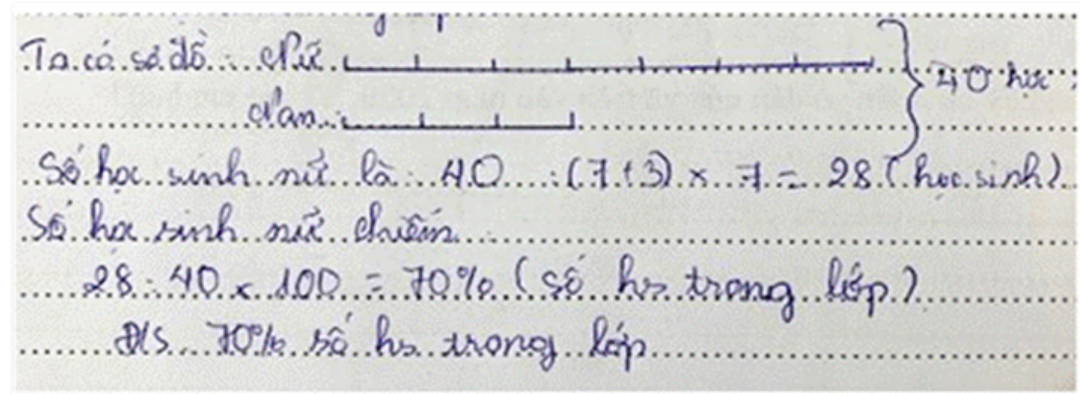

The number of girls is $(7+3) \times 7=10$ (students) Percent of pupils are girl $28: 40 \times 100=70 \%$ Answer: 70\% pupils are girls.

Figure 5. A students' answer to Exercise 5

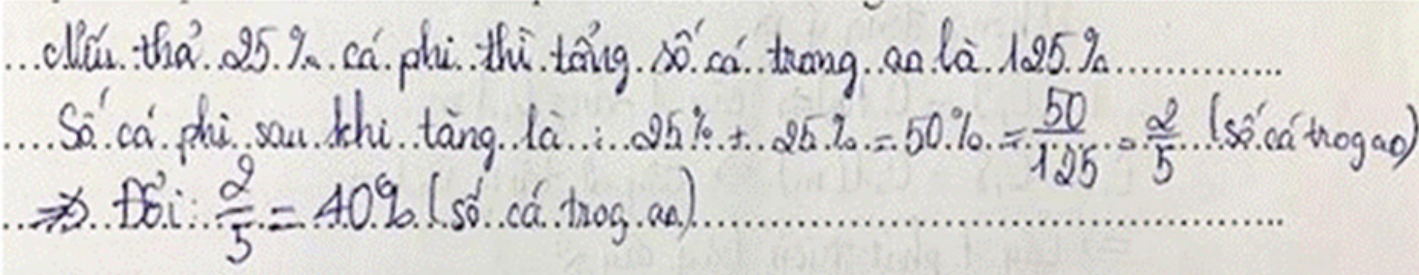

After adding, the number of fishes in the tank is $125 \%$

The number of gold fishes is $25 \%+25 \%=50 \%=\frac{50}{125}=\frac{2}{5}$ (to the number of fishes in the tank) Convert $\frac{2}{5}=40 \%$ (to the number of fishes in the tank)

Figure 6. A students' partly correct answer to Exercise 6

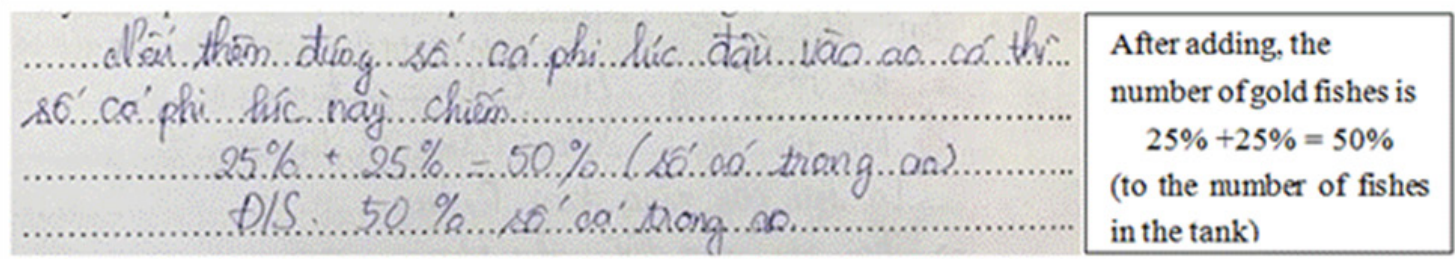

Figure 7. A students' incorrect answer to Exercise 6

\section{* Exercise 5}

Although all students had a correct response to Exercise 5(see Figure 5), there was only one student who performed to find $\frac{7}{10}$ and convert $\frac{7}{10}$ to $\frac{70}{100}=70 \%$. However, some students skipped converting $\frac{70}{100}=70 \%$ and had a wrong expression " $28: 40 \times 100=70 \%$ ".

In this solution, many students tried to find the number of girls by strategy based on the "sum-ratio" problem and apply operation $28: 40 \times 100$. This process was a routine way that they learnt to find percentage before. It was clear that the students did not discover " $\frac{7}{10}$ is the ratio of girls to the total of pupils from the ratio $\frac{3}{7}$ of boys to girls". The "sum -ratio" problem is quite familiar with the 4th graders in solving word problems, so in grade 5 they often based on the problem to find the answer for non-routine problems without concerning to relationship of given data. For Exercise 5, returning to a familiar problem was not an effective strategy.

\section{* Exercise 6}

There were 16/35 students who had the correct answer. However, they had many errors in reasoning (see Figure 6).

Instead of pointing out fraction $\frac{50}{125}$ based on division $50: 125$, a student responded incorrectly $50 \%=\frac{50}{125}$. In the other hand, "the number of fish" and "percentage of fish" were not distinguished.

Some students who answered the question incorrectly did not focus on the change of a rate of fishes at first and after adding (see Figure 7). 
The results obtained from our study pointed out some following issues:

- Many students can find the relationships of the ratio with fractions or decimals even though Vietnamese textbooks do not refer to this knowledge.

- The situation that all students gave an incorrect response to Exercise 3 (using subtraction where division is appropriate) showed that students had difficulty in discovering the concept of ratio as a comparison tool in a real context.

- Lack of the concept of equivalent ratio in Toan 4 causes some students' difficulties in solving non-routine word problems and real problems involving ratio and percentage at grade 5 .

- Students often used arithmetic operations and found percentage according to a routine formula, sometimes used the line diagram model in solving problem.

- Students were confused by the problems with many data as well as understanding the ratio of the two quantities and the basic principle of the ratio is multiplication.

- It could be seen that students tried to find a suitable strategy to make sense of their solution. They used strategies given by their teacher so that they got difficulties in completing the problems which had different contexts. In Exercise 5, if data "There are 40 pupils in Class 5/1" is not added, students can get the correct answer without using the "sum-ratio" problem because the new problem is the same as another problem in Toan 5 .

- There is no variety of using strategy in students' works. In each problem, almost students showed the same solving strategy. Moreover, the line diagram strategy was performed inappropriately. The diagram appeared as students solved problems returning to the "sum-ratio" problem (see Exercises 4 and 5) and were not useful to find the answer. Meanwhile, students skipped the line diagram, although it was possible to use it to represent ratio and percentage effectively in Exercises 3 and 6.

According to the results of the research, it is necessary to pay attention to building the concept of equivalent fractions as well as equivalent ratios and limiting the amount of time for "sum-ratio" and "difference-ratio" problems in teaching mathematics in grade 4 . Knowledge of ratio needs to be continued to teach in grade 5 , like the relationship of proportional quantities and ratios. For percentages, it is crucial to supply the conversion of a per cent into fractions and vice versa and add more solution strategies to each type of word problems related to percentage.

Besides, teachers need to provide more strategies such as making tables, looking for a pattern, etc. It can be concluded that using patterns helps students realize the constant ratio relationship of two proportional quantities that the previous methods cannot assist [10]. In Vietnam primary mathematical syllabus, in grades $1-3$, students are acquainted with the strategy of "look for a pattern" in solving problems related to numbers, shapes, and tables of addition and multiplication/

In short, the 5th- grade students have difficulties in understanding the concept of a ratio and applying ratio in problem-solving process. It is indispensable to be aware of these misconceptions and provide students with more effective strategies.

\section{Conclusions and Implications}

As we know, ratio and proportion are mathematical concepts that have many applications in real life. For example, we often hear terms like growth ratio or growth rate in everyday life. However, by analyzing the content of math textbooks in primary schools in Vietnam, we have found that students do not have the opportunity to practice how to solve many practical problems and find it difficult to choose appropriate strategies for each problem; this is clearly shown in the results of exercises 3,4,5 above. Therefore, in teaching mathematics on ratio and formula ratio in the new program in Vietnam, attention needs to be paid to:-Make students see the practical meaning of ratios and ratios. Strengthen practical exercises in which we need to use the ratio and proportion to solve the problem;-Help students avoid misunderstandings between the concepts of ratios and fractions; see the relationship between these two concepts;-Enhancing the practice for students to use multiple representations to find strategies to solve the problem. If the above-mentioned content is implemented in schools, we believe that mathematics education in Vietnam will avoid one thing that has been encountered for a long time, namely that mathematics is an abstract world far from real life.

\section{REFERENCES}

[1] Andini, W. \& Jupri A. (2017). Students Obstacles in Ratio and Proportion Learning. IOP Conf. Series: Journal of Physics, 812 (2017), 1-6.

[2] Bộ Giáodụcvà Đàotạo. (2018). Chươngtrình Giáo dục phổ thong môn Toán. HàNội.

[3] Celen Y. (2018). Misconceptions about the Ratio of Proportion of $7^{\text {th }}$ Grade Students. Journal of Modern Education Review, 8(1), 126-135.

[4] Chung, V.Q., Lai Đ.T., Đat, Đ.T., Lan T.N., Quang N.H., \& Son L.N. (2007). Phương pháp dạy học Toán ở tiểuhọc. Vietnam Education Publish House, Hanoi.

[5] Dougherty, B., Bryant, D. P., Bryant, B. R., \& Shin, M. (2017). Helping Students with Mathematics Difficulties Understand Ratios and Proportions. Teaching Exceptional Children, 49(2), 96-105. 
[6] Hoan,Đ.Đ. (editor), Ang, N., An, Đ.T., Chung, V.Q., \&Thuy, V.D. (2014). Toán 4.Vietnam Education Publish House, Hanoi.

[7] Hoan, Đ.Đ. (editor), Ang, N., An, Đ.T., Chung, V.Q., \&Thuy, V.D. (2014). Toán 5. Vietnam Education Publish House, Hanoi.

[8] Hien,T. D. (2012).Thựchành Giảitoántiểuhọc. University of Education Publish House, Hanoi.

[9] Kolovou, A. (2011).Mathematical problem solving in primary school. Doctor Thesis. Utrecht University, Netherlands.

[10] Loc, N.P. \& Phuong, N.T. (2020). Using the "Identifying a Pattern" Strategy to Solve Mathematical Word Problems of Proportional Quantities at Grade 5 - Vietnam. Universal Journal of Educational Research, 8(1), 105-111.

[11] Mahlabela, P. T. (2012). Learner Errors and Misconceptions in Ratio and Proportion: A Case Study of Grade 9 Learner from a Rural KwaZulu-Natal School. University of KwaZulu-Natal, South Africa.

[12] Ministry of Education Singapore. (2012). Mathematics
Syllabus Primary One to Five, Curriculum Planning and Development Division.

[13] National Council of Teachers of Mathematics (NCTM). (2006).Focusing on Ratio and Rate. Retrieved February 28, 2020, from www.nctm.org

[14] Ng, S.F. \& Lee, K. (2009). The Model Method: Singapore Children's Tool for Representing and Solving Algebraic Word Problems. Journal for Research in Mathematics Education, 40(3), 282-313.

[15] Phuong, N.T. (2017). Khái niệm tỉ số phần trăm trong sách giáo khoa Toán tiểu học Việt Nam và Singapore. Kỷyếu Hộithảo CIDMath6, 235-244. Ho Chi Minh city Education University Publish House.

[16] Project Maths Development Team (2012).Teaching and Learning Plan: Ratio and Proportion. Retrieved February 28, 2020, from www.projectmaths.ie.

[17] Seifi M., Haghverdi, M., \& Azizmohamadi, F. (2012).Recognition of Students' Difficulties in Solving Mathematical Word Problems from the Viewpoint of Teachers. Journal of Basic and Applied Scientific Research, 2(3), 2923-2928. 